\title{
PROFISSIONALIZAC̣ÃO DOCENTE EM UMA ESCOLA PRIVADA DE SETORES POPULARES: SEGUINDO O FIO DE ARIADNE
}

\author{
Rita de Cassia Ximenes Mury“ \\ Pontifícia Universidade Católica do Rio de Janeiro (PUC-Rio) \\ Isabel Alice Monteiro Lélis** \\ Pontifícia Universidade Católica do Rio de Janeiro (PUC-Rio)
}

\begin{abstract}
RESUMO: Este trabalho é parte de uma pesquisa realizada em escola privada frequentada por setores populares. Focalizando a profissionalização docente marcada por esse contexto, optou-se pela utilização das histórias de vida como principal instrumento para aferição dos dados. Os conceitos de trajetória, campo e habitus desenvolvidos por Bourdieu foram centrais na análise. Além disso, os estudos de Nóvoa, Valle e Fanfani ajudaram na construção e na discussão dos dados. A investigação evidencia um processo de profissionalização ímpar, marcado por uma aderência à profissão construída no processo de formação, na vivência da docência e por gosto aprendido, identificado pelas professoras como "vocação". Discute-se como as relações quase familiares estabelecidas nesse espaço fomentam um caminho singular à trajetória profissional docente. Finalmente, aponta-se a importância de que a profissionalização docente seja compreendida a partir dos contextos concretos de atuação e das trajetórias de vida dos professores, tendo em vista a heterogeneidade característica dessa profissão.
\end{abstract}

Palavras-chave: Profissionalização docente. Trajetórias de vida. Aderência. Setores populares.

http://dx.doi.org/10.1590/0102-4698141942

"Doutora em Ciências Humanas - Educação pela Pontifícia Universidade Católica do Rio de Janeiro (PUC. Rio). Professora no Departamento de Educação da mesma universidade e integrante do GEPPE - Grupo de Estudos e Pesquisa sobre o Professor e o Ensino. E-mail: ritamury@yahoo.com.br

" Doutora em Ciências Humanas - Educação pela Pontifícia Universidade Católica do Rio de Janeiro, com Pós-Doutorado pela Universidade de São Paulo (USP). Professora e pesquisadora do Departamento de Educação da Pontifícia Universidade Católica do Rio de Janeiro (PUC-Rio), coordenadora do GEPPE Grupo de Estudos e Pesquisa sobre o Professor e o Ensino. 


\section{TEACHER PROFESSIONALIZATION IN A PRIVATE SCHOOL SERVING POPULAR SECTORS: FOLLOWING ARIADNE'S THREAD}

ABSTRACT: This paper is part of a research conducted in a private school serving popular sectors. Focusing on teacher professionalization marked by this context, we opted to use life histories as the main instrument for data collection. The concepts of trajectory, field and habitus, developed by Bourdieu, were central in the analysis. Furthermore, studies by Nóvoa, Valle and Fanfani helped in the construction and discussion of data. The investigation shows a unique process of professionalization, marked by an attachment to the profession built in the training process, teaching experience and by a learned taste, identified by teachers as "vocation". This paper discusses how the almost family-like relationships established in this school foster a singular path to the teaching career. Finally, it points out the importance of understanding teacher professionalization from the concrete contexts of action and life trajectories, considering the heterogeneity characteristic of this profession.

Keywords: Teacher professionalization. Life trajectories. Attachment. Popular sectors.

\section{INTRODUÇÃO}

Compreender como se constitui a profissionalização docente em escolas privadas que atendem aos setores populares da sociedade a partir das histórias de vida desses professores foi o objetivo perseguido pela investigação que deu origem a este texto ${ }^{1}$. A pesquisa tinha como pressuposto o fato de que o trabalho das escolas privadas que atendem a alunos provenientes de famílias dos setores mais populares da sociedade não se integra àquele executado nas redes públicas de ensino e nas escolas privadas consideradas de elite, alvos de várias pesquisas no campo educacional ${ }^{2}$. O tema assumia, então, o lugar de "objeto silenciado", na literatura especializada, e foi sobre ele que se lançou esforços no intuito de questionar a construção da docência nesses espaços marcados por singularidades e dinâmicas específicas.

Como Teseu, no intuito de vencer o Minotauro, penetramos num labirinto de discussões que giram em torno da profissão docente, esperando dele sair com êxito. Desenrolamos o fio de Ariadne para garantir a saída em segurança, cientes do desafio de percorrer caminhos desconhecidos, cheios de meandros e riscos. Contudo, como o grande herói grego, lançamo-nos certas da necessidade e na expectativa dos frutos desse feito. Nesse sentido, a pesquisa procurou responder às seguintes questões: como a lógica de funcionamento do trabalho em instituições privadas que atendem aos setores populares na cidade do Rio 
de Janeiro influencia a constituição da profissionalização de seu corpo docente? Como as trajetórias de vida desses professores influenciam a constituição de seu habitus profissional no cotidiano dessas instituições?

\section{A DOCÊNCIA COMO PROFISSÃO}

Ao assumir a profissionalização docente como tema da pesquisa, claramente duas opções foram feitas: uma, a de afirmar a docência como profissão; outra, a de compreender essa profissão como uma construção histórica, envolvida e influenciada por contextos específicos e, por isso, marcada por diferentes características a partir de elementos agregados a ela de acordo com os espaços e tempos de atuação dos professores.

Tendo como referência os argumentos apresentados por Nóvoa (1991), é possível não apenas compreender a profissão docente como construção, mas, também, afirmá-la como um lugar efetivo da ação de profissionais que, historicamente, têm investido em sua constituição enquanto um grupo que domina um saber e um saber fazer específicos e, ainda, como um "corpo administrativo autônomo e hierarquizado" (NÓVOA, 1991, p. 121).

De acordo com o autor, tal processo de profissionalização é marcado, primeiro, pela estatização da profissão. A assunção, pelo Estado, ainda no século XVIII, do processo de escolarização transforma os professores, progressivamente, em funcionários, conferindo-lhes status a partir da realização de provas e concursos que lhes confere licença para o exercício da atividade docente. Com o processo de estatização, os docentes ficam, ao mesmo tempo, sujeitos a um movimento de controle ideológico e político, e de produção de um discurso próprio. O modelo ideal de docente fica a meio caminho entre o funcionário e o profissional livre, entre o controle e a autonomia.

Outra marca desse processo é o estabelecimento de uma formação específica para a profissão. O surgimento das escolas normais promove uma mutação sociológica nos profissionais do ensino primário, elevando-os a profissionais formados e preparados para a atividade docente. Esse movimento, contudo, traz questões relativas à própria identidade docente, na medida em que transforma o acesso a essa profissão docente numa aspiração de diferentes camadas sociais. De acordo com o autor (NÓVOA, 1991, p. 126), "nem burguês, nem notável, nem camponês, nem intelectual, nem artesão, o professor primário tem enormes dificuldades para se inserir profissionalmente".

No século XIX surgem as primeiras associações profissionais, última etapa do processo de profissionalização dos professores. Elas 
serão portadoras das reivindicações dos docentes, essencialmente relacionadas à melhoria do estatuto, ao controle da profissão e à definição de uma carreira.

O quadro desenhado por Nóvoa (1991) relativo à gênese e ao desenvolvimento da profissão docente, contudo, não pretende mostrar um movimento ascendente e linear de prestígio e sucesso. Ao contrário, traz à tona um processo permeado por continuidades, mas também por rupturas e contradições. $\mathrm{O}$ autor aponta o papel decisivo e reconhecido dado a esses profissionais até as primeiras décadas do século XX, como representantes da instituição escolar: "a escola e a instrução encarnam o progresso, e os docentes são seus agentes" (NÓVOA, 1991, p. 131). Contudo, denuncia seu crescente desprestígio, a partir de então, associado à crença de que um mundo pós-guerra em desenvolvimento necessita de uma nova escola, provocando uma "ruptura do equilíbrio sociológico do corpo docente" (NÓVOA, 1991, p. 132). Na medida em que a ideia mesma de progresso e as finalidades da escolarização são postas em questão, a função tradicional da docência se desagrega, e outra relação com a profissão precisa ser construída, agora baseada em incertezas e numa concepção multifuncional da atividade. Dessa ruptura apontada pelo autor, surgem como resultados, dentre outros, a complexificação de tarefas, a precarização das condições de trabalho e o chamado mal-estar docente, apontados hoje pela literatura especializada como questões que assolam a profissão.

Ao discutir a escola como uma construção histórica, Canário (2005) defende que essa nova maneira de olhar para o seu trabalho exige do professor uma nova relação com os alunos e com o conhecimento, ou seja, uma nova relação pedagógica. Estabelecida numa instituição que vive, hoje, um processo de mutação e não de crise $^{3}$, tal transformação deve atender a uma nova ordem política, social e econômica engendrada pela sociedade contemporânea. Assim, a própria forma escolar é colocada em xeque, na medida em que vivemos o que o autor classifica como um "tempo de incertezas".

Num momento em que a qualidade da educação toma vulto nas discussões não só no campo acadêmico, mas na sociedade, de forma mais ampla, o professor, entendido como um dos sujeitos centrais no processo ensino-aprendizagem, estabelecido na instituição escolar, é colocado no cerne dos debates. Pensar sua formação e trajetória profissional torna-se, nesse sentido, ponto importante na própria reflexão acerca dos processos educativos e, ainda mais, da educação que queremos oferecer através da escola.

A reestruturação do trabalho docente, provocada pelas reformas educacionais vivenciadas não só no Brasil, mas em outros países da 
América Latina, tem levado à sua intensificação e, consequentemente, a um processo de flexibilização e precarização da atividade pedagógica, gerando novos padrões de organização do trabalho escolar. Para além da necessidade de mais tempo dedicado à função, novas práticas e novos saberes têm sido exigidos dos profissionais docentes em seu contexto de trabalho. E um novo perfil desse trabalhador tem sido construído, aliado a novas exigências em sua formação profissional.

A massificação da escolaridade, possibilitando a inserção de novos alunos na instituição escolar, muitas vezes provenientes de setores socialmente excluídos, as transformações nas relações de poder entre as gerações e na estrutura e dinâmica dos grupos familiares e as inovações no campo das novas tecnologias da informação e da comunicação são ainda, de acordo com Fanfani (2007), alguns dos fatores que trazem novos desafios ao papel do professor. Funcionando como pano de fundo para o cotidiano do trabalho docente desenvolvido nas escolas, tais mudanças sociais acentuam o caráter heterogêneo e multifuncional da escola e de seus profissionais, e provocam, muitas vezes, uma sensação de mal-estar entre os docentes que percebem não corresponderem às expectativas que lhe são colocadas.

Fanfani (2007, p. 22) aponta que as mudanças provocadas pelas recentes reformas educacionais, inclusive no Brasil, indicam que o ofício docente deve se articular de uma nova forma tendo em vista o quadro atual que configura a atuação desses profissionais. Nesse sentido, aspectos relativos ao fazer diário dos professores, marcados por componentes técnicos, humanos e políticos devem combinar-se numa nova trama a fim de possibilitar um real enfrentamento dos desafios atuais colocados à profissão.

Tendo em vista o contexto exposto acima e as especificidades do trabalho dos professores a partir das mudanças nas relações sociais e de trabalho ocorridas nas últimas décadas, assumimos para esse estudo a ideia da profissionalização docente compreendida como um processo de socialização construído durante a trajetória de vida do professor, levando-se em conta suas motivações objetivas e subjetivas para a aderência e a permanência no ofício. Tal processo acontece permeado pelas determinações e possibilidades propostas por seu espaço de atuação, nesse caso específico, as escolas privadas de setores populares. Sem desvincular esses professores da categoria docente como um todo e das discussões propostas para sua compreensão como profissão, partese do pressuposto de que a atuação nesses estabelecimentos possibilita a construção e socialização de saberes específicos que, se alimentados mutuamente, constituem e são constituídos na relação com os pares, a partir de suas trajetórias formativas, concomitantemente individuais 
e coletivas. Cabe, então, questionar que tipo de relação profissional é estabelecida nessas instituições e, ainda, que compreensão os sujeitos aí atuantes têm do que é ser profissional.

\section{ENTRE O PÚBLICO E O PRIVADO}

Se Nóvoa (1991) afirma a estatização docente como um momento importante da profissionalização dos professores, a realidade brasileira faz com que instituições públicas e privadas convivam e estabeleçam grande diversificação na estrutura educacional ${ }^{4}$, tanto do ponto de vista do trabalho e da carreira docentes quanto do ponto de vista da oferta de vagas e da qualidade do ensino ofertado. Em estudo coordenado por Gatti (2009) acerca dos professores do Brasil, averiguou-se que em $2006^{5}$ foram ofertados 2.949 .428 postos de trabalho para professores e outros profissionais do ensino no país. Desse total, $82,6 \%$ provinham de estabelecimentos públicos, e o restante partia da iniciativa privada.

Esses números têm óbvios desdobramentos no que tange ao financiamento da Educação no país, à valorização e carreira docentes e, consequentemente, ao processo de profissionalização desse grupo, cuja grande maioria trabalha no setor público. É preciso ter em mente, contudo, que o setor privado da educação também comporta um número enorme de profissionais e, diferentemente do ensino público, está sujeito a um tipo de regulação diferenciada, não centralizada e baseada em critérios distintos de acordo com cada instituição de ensino. Da mesma forma, seus profissionais, não integrando redes de ensino (mesmo tendo-se em mente os problemas enfrentados pelas redes públicas no Brasil) estão sujeitos a modelos diferenciados de gestão organizacional e pedagógica e não compartilham com os profissionais das redes públicas a segurança de uma contratação por concurso público.

Cabe destacar, também, a enorme diversidade encontrada dentro desse grupo de escolas privadas. De acordo com o presidente ${ }^{6}$ do Sindicato dos Professores do Rio de Janeiro (Sinpro-Rio), apenas nessa cidade quatro grandes grupos de escolas privadas podem ser encontradas: aquelas consideradas de elite, por atenderem às camadas economicamente mais favorecidas da sociedade; as que funcionam atreladas a instituições religiosas, atendendo a alunos oriundos de classes menos favorecidas; as instituições ligadas a grandes redes de ensino que se propagam por diferentes bairros da cidade com o mesmo nome, material didático e linha pedagógica; e outras pequenas escolas, abertas por particulares, geralmente dirigidas 
pela(o) própria(o) proprietária(o). Nesses diferentes grupos, distintas relações de trabalho são estabelecidas e, internamente, cada grupo diferencia-se, apontando a heterogeneidade da oferta escolar.

Para empreender tal investigação, optamos por situá-la em apenas uma escola, tendo em vista a heterogeneidade apontada acima. Selecionamos, então, uma das escolas estudadas pela pesquisa-mãe, pertencente ao quarto grupo citado acima, aqui denominada Escola da Ladeira ${ }^{7}$. Tal escolha se deu, especialmente, por se tratar de uma instituição com mais de quarenta anos de existência.

Fundada em 1961 por três professoras para atender aos seus próprios filhos no então Jardim de Infância e Pré-Primário, em 2011, durante a pesquisa, a instituição possuía um corpo docente composto por 11 professoras - uma delas sendo a proprietária e diretora da instituição - e dois professores, todos contratados por regime de trabalho celetista, alguns com carga horária dobrada, atuando no EF1 e no EF2, concomitantemente, em turnos alternados. Vale sinalizar que quatro professoras desse total, incluindo a atual diretora, trabalhavam na Escola da Ladeira há mais de 10 anos, e três há menos de um ano, e a faixa etária delas varia entre 30 e 55 anos. De acordo com a diretora da escola, não havia rodízio de professores na instituição. Mesmo assim, durante a realização da pesquisa - março a outubro de 2010 duas professoras foram substituídas por terem deixado a escola.

Dados aferidos a partir do questionário aplicado ao corpo docente da Escola da Ladeira indicaram que cinco dos onze respondentes trabalhavam apenas nessa instituição de ensino, e outros seis trabalhavam em duas ou mais escolas; destes, cinco trabalhavam também em instituições públicas estaduais. Isso mostra que tais professoras passaram por concurso e atuam credenciadas por tal processo. Os dados indicam que sete professoras da instituição possuem Pós-graduação (uma em nível de Mestrado e seis em nível de Especialização), outras duas concluíram o Ensino Superior e duas professoras possuíam apenas o Curso Normal em nível médio.

A escola mantinha, ainda, uma assistente de direção, responsável por cuidar de todo o movimento da escola durante o dia, nos dois turnos, desde oferecer atendimento aos pais, alunos e professores quando solicitada, até cuidar da documentação entregue ao contador, além de ser responsável pelo trânsito de alunos pela escola, por apoiar os professores no que tange à disciplina em sala de aula e providenciar o lanche dos alunos, vendido na escola durante o recreio.

Instalada num bairro tradicional do Rio de Janeiro, a escola funcionava num prédio histórico, cuja fachada havia sido recentemente reformada. Se não fosse a placa indicando a entrada, não 
seria possível identificar, naquele local, a presença de uma instituição escolar. Tratava-se, na verdade, de uma casa antiga, de arquitetura que remetia ao período colonial, adaptada internamente para esse fim.

Atendendo da Educação Infantil (EI) ao $9^{\circ}$ ano do Ensino Fundamental (EF), em horário parcial ou integral e, ainda, oferecendo ensino supletivo à distância para alunos de Ensino Fundamental e Médio, a escola se mantinha com um corpo discente de cerca de 130 alunos, com turmas que variavam em quantidade, sendo mais numerosas aquelas dedicadas ao EF2. O público-alvo da Escola da Ladeira era então composto, exatamente, pelos moradores do entorno, caracterizado, tanto pela diretora da escola quanto por suas professoras, como de classe média baixa.

A mensalidade na Escola da Ladeira variava entre R $\$ 260,00$ e R $\$$ 470,00 para os alunos de horário parcial - a grande maioria dos atendidos pela instituição. De acordo com a atual diretora e proprietária da escola, há um preço de tabela, mas há também abertura para negociações com famílias de renda mais baixa. Por isso, não há um valor fixo para todos.

Esperava-se que uma escola mais antiga, com uma caminhada já delineada e um corpo docente com características próprias, atendesse melhor aos objetivos propostos para esta investigação. Se a intenção era investigar como a lógica de funcionamento de uma instituição específica influenciaria a profissionalização de seu corpo docente, consideramos que essa escola, com uma história construída e, portanto, com práticas e concepções estabelecidas, nos permitiria acessar com maior propriedade sua influência sobre o processo de profissionalização de seu corpo docente. Importava-nos conhecer que professores aí atuavam, e como construíam sua identidade profissional a partir de sua prática cotidiana e de suas trajetórias pessoais.

\section{A PESQUISA EM AC̣̃̃O}

A partir dessa escolha, a pesquisa foi iniciada com a aplicação e análise do questionário elaborado pelo GEPPE ao corpo docente da escola ${ }^{8}$. Tal instrumento, aplicado em todas as escolas que compunham a pesquisa, pretendia desenhar um quadro dos docentes dessas instituições, abordando aspectos relacionados ao perfil sociodemográfico do grupo, à sua formação e ao trabalho específico nessas escolas. Pretendia-se que esse questionário informasse, ainda que de forma provisória, que grupo era esse, sujeito/objeto da pesquisa, a ser encontrado no campo de investigação através de uma caracterização que incluísse dados pessoais e profissionais. 
Informações relacionadas a local de moradia e renda mensal, dentre outras, ajudariam a pensar a escolha profissional e a opção por essa instituição específica para o trabalho.

Os dados mostraram que, no que tange à renda mensal, seis delas afirmaram aferir um salário bruto superior a $\mathrm{R} \$ 1.500,00$. As demais afirmaram receber menos que isso; duas professoras, inclusive, asseveraram que sua renda não alcançava a faixa de $\mathrm{R} \$$ 500,00 mensais. Esse dado apontava para a baixa remuneração desse corpo docente; sendo possível afirmar que aquelas que possuíam uma renda melhor eram exatamente as que trabalhavam em mais de uma instituição de ensino, superando as 30 horas de trabalho semanais dedicadas à docência. Esse quadro inicial nos ajudou a perceber esse corpo docente oriundo também de setores populares.

No momento seguinte, a pesquisa foi realizada em campo tendo como instrumentos a observação e a entrevista. No que diz respeito à observação, pretendia-se apreender o dia a dia do trabalho docente na instituição selecionada, buscando captar a dinâmica do trabalho aí desenvolvido. Com a concordância das professoras, fizemos observações em todas as turmas do Ensino Fundamental 1 (EF1) e, também, participamos de ensaios e preparações para apresentações e festas. Além de conhecer o dia a dia das salas de aula, perceber como flui a cultura escolar e investigar aspectos relativos ao trabalho docente na instituição, tivemos a possibilidade de nos aproximarmos das professoras e, assim, apresentar-lhes a pesquisa, convidando-as para que participassem das entrevistas. $O$ intuito primeiro, de fato, era que tornássemos familiar aquele ambiente. De acordo com Tura (2003, p. 185), a observação, enquanto técnica de pesquisa, pode proporcionar uma maior aproximação entre "O acontecer da vida social e a análise do ponto de vista dos atores". Ela possibilita a imersão do pesquisador no campo e a compreensão do significado dado às suas ações pelos próprios sujeitos. Assim, procuramos perceber como os docentes agem em sua atividade profissional, como mobilizam seu capital pedagógico9 (LÉLIS, 2014) em seu fazer cotidiano e como se dão as relações entre eles, com a direção e com o corpo discente.

Criado com o intuito de orientar as narrativas, mas sempre objetivando apreender o máximo de informações e provocar a fala dos entrevistados, o roteiro utilizado para as entrevistas nasceu, exatamente, da análise dos questionários e das observações realizadas na escola. Das 13 professoras que compunham o corpo docente da Escola da Ladeira, 11 concederam entrevistas.

A utilização das histórias de vida como método de pesquisa possibilitou reunir o en pessoal e o en profissional (NÓVOA, 2007, p. 15), 
evidenciando a complementaridade desses aspectos. Possibilitou, também, acessar a subjetividade dos professores, trazendo-os para o centro do debate a partir da compreensão de suas próprias impressões e ideias acerca de sua prática diária e de seu trabalho nessa escola, perpassada por sua opção e formação profissionais e por seus projetos futuros. O trabalho incidiu, então, sobre as trajetórias desses profissionais, lidas à luz do contexto e dos diferentes campos em que transita o sujeito social (BOURDIEU, 1996).

Tal abordagem investigativa, propondo a mediação entre a história individual e a história social, possibilitou-nos acessar, mais do que os fatos em si, os significados dados a esses fatos pelos sujeitos que os narravam (LÉLIS; NASCIMENTO, 2010, p. 258). Ao expor sua própria vida, imbuído de sua cultura, de seu modo de viver e de suas experiências, ao mesmo tempo pessoais e coletivas, cada sujeito lhe confere sentido e coerência. Dessa forma, narra a história do meio em que vive e de seus grupos de contato, permitindo ao pesquisador acessar o contexto de suas escolhas e opções, de seus valores e modos de ver o mundo. O projeto profissional de um sujeito pode ser conhecido, assim, no conjunto de seus tantos projetos de vida, que se cruzam a partir de suas escolhas e vivências (JOSSO, 2006).

\section{HISTÓRIAS E TRAJETÓRIAS: ALGUMAS DESCOBERTAS}

Em contraposição à situação da maioria das escolas públicas no Brasil, a escola privada é, de certa forma, cercada de uma aura de eficácia, de bons resultados e, principalmente, de boas condições de trabalho. Em certa medida, essa pesquisa põe em cena aquilo que Lélis et al. (2010) denomina "mito da superioridade da escola privada", descortinando um cenário diferente, sim, daquele encontrado na escola pública brasileira em muitos aspectos, mas não necessariamente melhor.

Falar de profissionalização docente nessa escola, marcada pela atuação no espaço privado e, ainda, pelo atendimento a alunos provenientes da baixa classe média, é falar de um percurso ímpar, singular. Os caminhos trilhados nesse espaço são os possíveis, na conjugação entre as trajetórias de suas professoras e as marcas organizacionais da instituição. Se tal caminho se aproxima, em alguns aspectos, daquele vivenciado pelos professores de escolas públicas ou mesmo de escolas que atendem às elites da sociedade, em outros se distancia e toma corpo de forma particular. Não é possível afirmar, porém, que não há um percurso de profissionalização. Isso seria negar a própria profissão e a individualidade de seus atores. É possível, 
isto sim, pontuar avanços e retrocessos, e apontar para necessárias rupturas em busca de um modelo, se não idealizado, ao menos mais efetivo na concretude da escola.

A heterogeneidademarcaa escolademassasnacontemporaneidade. Percebida principalmente na dimensão humanada da tarefa pedagógica - nos discentes, no corpo docente e no contexto sociocultural - essa heterogeneidade faz da atividade docente uma tarefa complexificada por processos que, se antes aconteciam nos espaços externos a ela, hoje se concretizam nos seus pátios, nos seus corredores e, especialmente, nas relações aí estabelecidas (FORMOSINHO, 2009). Falar de profissionalização docente, então, não pode prescindir de um olhar sobre a pluralidade característica não apenas do público atendido pela escola, mas também dos sujeitos que, incitados por diferentes motivações, escolhem a docência como profissão e têm esse campo específico para atuação.

"Tão importante para a realização e sucesso profissional como a formação é a escolha da profissão", afirma Formosinho (2009, p.32). Olhar para a profissionalização desse grupo não poderia prescindir, então, de um olhar para sua aderência ${ }^{10}$ à profissão. De acordo com Autor (2011), o termo aderência aqui utilizado indica uma opção pelo magistério a posteriori, num processo construído durante o curso de formação inicial ou mesmo já na prática da atividade docente. Essa realidade aparece nos relatos das entrevistadas questionadas sobre sua opção pelo magistério, indicando que a escolha se deu, de fato, após o contato com a profissão, no processo de formação ou na prática docente, negando inicialmente a ideia de uma escolha realizada a partir de um desejo anterior de ser professora.

Nos relatos, fica claro como, para essas professoras, a aderência à profissão está ligada ao gosto aprendido. Interessada na escolha profissional do magistério por um grupo de universitários, o estudo de Valle (2006, p. 179) defende que essa opção não é feita com base em características de personalidade, como poderia aceitar o senso comum. Ao contrário, elementos de ordem econômica, política e educacional, como flutuações do mercado, especialização das áreas profissionais e acesso a determinados cursos e instituições de ensino, delimitados num certo ambiente sociocultural e momento histórico, norteariam a escolha pessoal e o percurso profissional de cada sujeito, ao influenciar, de alguma maneira, no futuro de cada um.

Em termos bourdieusianos, compreendemos as escolhas individuais como vinculadas às estruturas objetivas dos campos. Logo, é necessário entender tal processo destacando, para isso, a influência da socialização primária - familiar - e, ainda, as experiências 
escolares. A posição social dos pais, as atividades que exercem e sua posição sociocultural ou nível de escolarização, bem como sua própria escolaridade circunscrevem o leque de possibilidades utilizado como referência para a escolha profissional. Embora algumas das professoras entrevistadas afirmem não terem sido boas alunas e precisarem de empenho e esforço para a aprovação e a aquisição de títulos acadêmicos, as mesmas indicam o valor dado pela família à prática do estudo e um gosto desenvolvido pelos estudos desde o início da escolaridade.

A docência, para esse grupo de professoras, aparece, como uma escolha, sim, mas feita dentro de um campo de possíveis (BOURDIEU, 2007), num processo de aderência definido a posteriori. Apesar de terem sido afastadas de seus sonhos e desejos, impossíveis de serem materializados em determinado espaço e tempo de suas vidas, suas trajetórias individuais as aproximaram de uma vocação descoberta na lida do fazer pedagógico, aprendida e desenvolvida tanto na formação quanto na prática profissional. E é preciso ter em mente que se hoje atendem, na Escola da Ladeira, a alunos provenientes da baixa classe média, elas mesmas são fruto dos setores populares da sociedade. Portanto, suas trajetórias e a aderência à profissão trazem as marcas desse contexto.

Nos relatos, é possível perceber que, independente do segmento no qual atuam, ou da formação específica que têm, as professoras entrevistadas, quase que com unanimidade, apostam no gosto, no prazer e no dom como essenciais para a escolha do magistério como profissão hoje. No imaginário desses profissionais, a docência parece estar ligada ao dom, à vocação, e essa constatação suscita reflexões interessantes. Primeiro, é possível questionar como, mesmo entre professoras tituladas em nível superior e que desenvolveram o gosto pela profissão a posteriori, em sua própria experiência, essa categoria está marcada pela ideia de vocação. Depois, sobre a possibilidade de que o apego ao prazer pessoal, e mesmo a facilidade de acesso à formação e ao mercado de trabalho, apareçam como substitutos para a aderência à profissão docente, já que o lugar social ocupado hoje pelo professor e a crescente desvalorização de seu papel não atraem para a docência.

Valle (2002) compreende a "identidade vocacional" como herança das Escolas Normais, construída com base numa concepção missionária do magistério e em virtudes morais e espirituais. Para a pesquisadora, a vocação identificava a docência com o papel social da mulher, voltado para o cuidado e o afeto, e estimulava uma prática pedagógica pautada em valores humanistas. Valle (2002, p. 212), contudo, adverte:

Ora, tanto no campo sociológico quanto educacional os estudos sobre dom e vocação se multiplicam sistematicamente e demonstram que não se pode mais reduzi-los às ideias de disposição inata, de aptidão natural, de dádiva divina ou 
de graça, que remetem aos sentimentos de generosidade, de desprendimento e de sacrifício. [...] É necessário mostrar como, e em relação a que expectativas, se constrói socialmente em certos indivíduos o sentimento de uma vocação singular. Esses sentidos estão frequentemente subjacentes às escolhas pessoais, conferindo às profissões, ou a algumas delas, uma especificidade própria, sui generis, que delineia um determinado perfil profissional e conduz a um tipo particular de engajamento.

A ideia de uma vocação construída no dia a dia da sala de aula parece saltar das narrativas. Muitas professoras, porém, compreendem que "encontraram" sua vocação, como o despertar de algo adormecido. Tal vocação aparece, dessa forma, ligada ao gosto, ao prazer do trabalho em sala de aula. Mesmo não desconhecendo os problemas inerentes à profissão, tal ideia traria sentido a suas opções e ajudaria a viver dia a dia uma profissão não escolhida, mas a qual se aderiu por força das trajetórias. Os afazeres da profissão - ensinar, estar com os alunos, planejar, gerenciar as relações - não aparecem como algo desejável para que alguém escolha ser professor hoje. De forma genérica, o prazer e o gosto indicam o sentido da "missão" que assumem em seu fazer cotidiano, expressando a força de um imaginário que impregna a docência em seus vários níveis.

Tratando das mudanças sociais que interferem no trabalho docente e, consequentemente, no processo de profissionalização do magistério na América Latina, Fanfani (2007) aponta que um aspecto "vocacional" é inerente à profissão. Uma vocação, contudo, não mais compreendida como desapego, como característica pessoal ou marcada pela gratuidade, pelo desinteresse e pelo sacrifício. Sendo o trabalho docente realizado na relação com o outro, compromisso, respeito e cuidado são aspectos inerentes a essa função, e esse plus ético, conforme definido pelo autor, poderia ser denominado como um elemento vocacional. Contudo, compreendido como necessário para a realização do trabalho docente, tal elemento deveria ser desenvolvido a partir de políticas de formação que o levassem em conta e, além disso, fortalecido por dispositivos coletivos de gestão do próprio corpo docente.

O sentido vocacional da docência seria, dessa forma, não uma característica individual que definiria a opção pela profissão, mas sim um elemento do processo de profissionalização docente, a ser construído e estimulado de forma intencional nos programas de formação. Aderir à profissão poderia de fato, então, despertar um sentido vocacional, mas marcado pela busca de um desenvolvimento que favorecesse a construção de uma identidade profissional, alimentada e alicerçada num processo de formação e reflexão constantes.

As narrativas das professoras da Escola da Ladeira indicam que muitas delas buscam esse desenvolvimento através de suas 
práticas formativas e de sua atuação cotidiana neste e em outros espaços. Sua aderência à profissão, feita a posteriori, não impediria, então, o desenvolvimento dessa vocação. Esse desenvolvimento, se incentivado pela instituição e vivido de forma consciente poderia, talvez, produzir rupturas com modelos e práticas vigentes.

\section{PROFISSIONALIZAC̣ÃO DOCENTE E CONTEXTO DE AC̣ÃO}

Mesmo num contexto de desvalorização da profissão docente, esse grupo busca, dentro de seus limites, a qualificação profissional através de uma certificação para a docência. A procura por capacitação e cursos de formação continuada é uma opção pessoal, tomada por aquelas que acreditam em sua profissão e, principalmente, esperam alcançar um desenvolvimento em sua carreira docente. Mesmo cientes do quadro que emoldura a profissão hoje, e afirmando a necessidade de maior valorização, inclusive salarial, para sua função, essas professoras, de forma geral, investem o possível em sua formação e na aquisição de um capital cultural institucionalizado ${ }^{11}$ (BOURDIEU, 2007) que lhes possibilite crescimento na carreira docente, indicando que possuem expectativas; percebem no seu fazer a possibilidade de ir além do que já foram, e de crescer profissionalmente. Sua formação atende ao que lhes é exigido legalmente e, para a maioria, é o ponto de partida para outros caminhos almejados.

A profissionalização docente, acessada a partir das histórias de vida dessas professoras, é um percurso, um caminho a ser trilhado. E, nesse percurso, elas são submetidas a situações ímpares, características da estrutura organizacional de uma escola privada que atende aos setores populares da sociedade. Desde sua chegada a esse espaço institucional até o trabalho cotidiano nela desenvolvido, as marcas dessa instituição vão ajudando a moldar seu habitus profissional expresso tanto na relação pedagógica - desde o planejamento das aulas até as opções didático-metodológicas - quanto na relação com os alunos e com os demais educadores da instituição. E são essas marcas que tornam esse processo único.

Numa instituição dirigida de forma familiar, passada de mãe para filha, as relações estabelecidas se sobrepõem ao profissional e se configuram, também, como familiares. O dia a dia da escola é permeado pelos laços de amizade e confiança estabelecidos entre professoras e diretora. Se isso traz certo bem-estar traduzido na boa lida e no acesso direto à direção para a resolução de possíveis conflitos e dúvidas, também impõe inibições no que tange a reivindicações e, mesmo, 
discordâncias, por mais simples que sejam. As professoras expressam certa gratidão à diretora, apontando em seus relatos momentos de sua vida pessoal nos quais ela thes teria ajudado. Compreendem, ainda, que a confiança depositada em seu trabalho decorre, em grande medida, da confiança na pessoa mais que no profissional.

As relações pessoais, quase familiares, estabelecidas nessa escola garantiriam, na verdade, uma rede de segurança para a própria escola. Desprovida de uma coordenação pedagógica, a regulação do trabalho desenvolvido é realizada pela diretora, e toma como caminho principal a afetividade. As professoras, tendo acessado a escola e conseguido um emprego, em geral, por indicação de alguém próximo à direção, se sentem acolhidas e "em casa". Assim, todas assumem a responsabilidade pela instituição e pelo trabalho ali desenvolvido.

O espaço em que a escola funciona - uma casa adaptada, na qual ainda vive, no segundo andar, a ex-diretora e fundadora da instituição ajudaria a manter um clima de proximidade e a impor um caráter quase doméstico ao trabalho desenvolvido. Da janela do andar de cima, a fundadora dá orientações durante o recreio, por exemplo, e troca ideias com o corpo docente sobre o trabalho, embora não mais responda pela instituição. As professoras mais antigas expressam, em seus relatos, gratidão e ela, indicando seu papel na aprendizagem do ofício no início de suas carreiras, quando a ex-diretora entrava nas salas durante as aulas para verificar o trabalho e orientar o processo, inclusive assumindo a gestão da aula. Comprometidas com o fazer pedagógico, contudo, as professoras vivem a tensão entre a relação afetiva e a racionalidade técnica de sua função, que lhes exige, dia a dia, a necessária competência para o trabalho pedagógico em todas as suas dimensões. As orientações são tidas como regras e, para esse corpo docente, parece ser a garantia da qualidade que julgam pertinente a seu trabalho.

Tais relações construídas não em rede, mas em linhas retas que apontam diretamente para a pessoa da diretora, fazem com que esse corpo docente não sinta falta, de forma geral, de uma coordenação pedagógica, cujo papel seria oferecer-lhe um olhar de fora da sala de aula e proporcionar um debate constante acerca das práticas desenvolvidas na escola. Trocar ideias com a diretora já parece suficiente, e a regulação do trabalho, realizada via afetividade, acaba por perpetuar um idioma pedagógico institucional que valorizaria a transmissão de conteúdos e o trabalho individualizado desse corpo docente e, ainda, uma aparente sensação de liberdade e de autonomia.

Paradoxalmente, essas professoras se sentem livres para agir como querem, para tomar decisões relacionadas ao seu trabalho e aos seus alunos. $\mathrm{O}$ trabalho individualizado, contudo, não significa ter 
autonomia. Ao contrário, essa rede de segurança, ao que parece, manteria os profissionais da escola agindo dentro das expectativas da direção e da ideia veiculada aos pais acerca da proposta da escola. Esse quadro, é claro, é comum a outras escolas. Toma novo significado nesse contexto, porém, na medida em que as professoras não parecem perceber que sem espaços para discussão, poucas brechas são abertas para colocar em questão seu próprio fazer. Possuidoras de um capital pedagógico (LÉLIS, 2014) construído nas trilhas percorridas por cada uma, essa instituição possibilita poucos espaços para a sua revisão e reconstrução.

A preocupação demonstrada pelas professoras para com a ausência dos pais na escola e sua demissão no que tange ao desenvolvimento escolar dos filhos fornece indícios sobre o caráter profissional dado por elas mesmas à sua atuação. Mesmo que questionemos a relação estabelecida entre família e escola e que reconheçamos a necessidade de abertura de ambas as instituições para o diálogo, tal preocupação demonstra como esse corpo docente sente as mudanças que têm envolvido o trabalho do professor nas últimas décadas e, mais, sua preocupação com a realização de sua atividade. Lidar com as famílias é um dos aspectos da profissão docente.

Tal preocupação demonstra o olhar dessas professoras sobre a aprendizagem dos alunos. Em que pesem as questões levantadas acerca da ênfase na transmissão de conteúdos e nas atividades rotineiras percebidas no trabalho desenvolvido por elas, não seria possível negar que elas esperam que seus alunos aprendam. E buscam o apoio da família para isso, lançando mão de um recurso que lhes é conhecido a partir de suas próprias experiências escolares.

As experiências vividas na Escola da Ladeira delimitam, até certo ponto, uma trilha na qual se constitui a identidade profissional dessas professoras. No entanto, possuidoras de um habitus profissional híbrido e adaptável (SETTON, 2002), elas não estão totalmente cerceadas por essa instituição. Ao contrário, suas trajetórias demonstram como outros caminhos têm sido buscados por muitas delas. Mesmo considerando-se satisfeitas em trabalhar nessa escola, elas têm projetos, sonhos, muitos dos quais vislumbram novas frentes para seu desenvolvimento na profissão.

Dessa forma, reafirmamos aqui que essas professoras vivem um processo de profissionalização singular. Em que pesem os muitos aspectos problematizados, as professoras dessa escola, de forma geral, afirmam o gosto aprendido pela profissão e pelo que ela lhes proporciona em termos, inclusive, de ascensão social. Em sua trajetória, constroem sua profissionalização trilhando pelos caminhos possíveis, mas sempre vislumbrando outros horizontes. 


\section{CONSIDERACְÕES FINAIS}

Perscrutando as idas e vindas de trajetórias únicas e singulares e, ao mesmo tempo, convergentes, a investigação se revelou como mais um fio, tecido em meio a tantos outros, propondo uma saída possível para o labirinto aberto pelas muitas discussões relativas à profissão docente. Como Teseu no labirinto após derrotar o Minotauro, importa-nos seguir esse fio para dele sair; diferentemente do herói grego, contudo, intentamos voltar a ele muitas vezes; seguimos o fio escolhido conscientes de que muitos outros nos levariam - por distintos corredores - a outras saídas.

Entrar na Escola da Ladeira, percorrer seus espaços, suas salas de aula, conhecer seus alunos, acompanhar seu corpo docente em atividade e nos aproximarmos de suas histórias e trajetórias através das entrevistas nos possibilitou apreender os caminhos trilhados por esses profissionais. Contudo, se isso nos aproximou de sua atividade cotidiana e de suas percepções acerca de sua própria profissão, é certo que não nos possibilita generalizar ideias ou mesmo acreditar que tudo foi compreendido e analisado. Ao contrário, tal aproximação mostra que esse espaço concreto - como tantos outros nos quais a atividade docente se desenvolve - vive nuances e tensões cotidianas, que marcam os docentes tanto em seu fazer pedagógico quanto nos sentidos que imprimem a essa tarefa.

O labirinto que cerca a profissão docente não é armadilha. Inversamente, é possibilidade; é multiplicidade de olhares e vozes; é a concretude da heterogeneidade de seus atores e de suas ações. Exatamente por isso, este texto não pretende propor conclusões ou proposições, mas suscitar questões, problematizando o processo de profissionalização docente de professoras que, atuando numa escola privada que atende à classe média baixa - aqui denominada Escola da Ladeira - têm sua identidade profissional e sua prática marcadas por esse contexto específico em constante diálogo com suas histórias de vida.

Pensar a profissionalização docente poderia nos levar a supor ou mesmo a buscar um caminho ideal para esse processo. Pensar em aspectos como formação inicial e continuada de qualidade, valorização social e salarial, desenvolvimento de uma carreira docente, boas condições de trabalho, carga horária que contemplasse o trabalho desenvolvido pelos profissionais fora da sala de aula, espaços institucionalizados de planejamento e discussão acerca do trabalho desenvolvido na escola, dentre outros, seria apontar para uma profissão sonhada, idealizada no contexto concreto da escola brasileira, seja ela pública ou privada. Ao contrário disso, esse trabalho 
procurou perseguir a concretude da profissionalização docente numa escola específica, buscando compreender alguns de seus limites e avanços, procurando ouvir a vOz de seus atores e perceber como se dá esse processo, na sua experiência, em seus próprios termos.

\section{REFERÊNCIAS}

BOURDIEU, P. Razões práticas: sobre a teoria da ação. 9. ed. Campinas, SP: Papirus, 1996.

BOURDIEU, P. Os três estados do capital cultural. In: NOGUEIRA, M. A.; CATANI, A. (Org.) Escritos de Educação. 9. ed. Petrópolis, RJ: Vozes, 2007. p. 71-79.

CANÁRIO, R. O que é a escola? Um “olhar” sociológico. Porto, Portugal: Porto Editora, 2005. Colecção Ciências da Educação - Século XXI.

FANFANI, E. T. Consideraciones sociologicas sobre profesionalización docente. Educação \& Sociedade, Campinas, v. 28, n. 99, p. 335-353, mai./aug. 2007.

FORMOSINHO, J. (coord.) Formação de professores: aprendizagem profissional e acção docente. Colecção Currículo, Políticas e Práticas. Porto, Portugal: Porto Editora, 2009.

GATTI, B. A. (coord.); BARRETO, E. S. Professores do Brasil: impasses e desafios. Brasília: Unesco, 2009.

JOSSO, M. Os relatos de histórias de vida como desvelamento dos desafios existenciais da formação e do conhecimento: destinos sócio-culturais e projetos de vida programados na invenção de si. In: SOUZA, E. C.; ABRAHÃO, M. H. B. Tempos, narrativas e ficç̃es: a invenção de si. Porto Alegre: EDIPUCRS, 2006. p. 21-40.

LÉLIS, I.; NASCIMENTO M. G. Trajetórias de professores: a pesquisa com histórias de vida. In: MENDONÇA, A. W. (Org.) História e Educação: dialogando com as fontes. Rio de Janeiro: Forma e Ação, 2010.

LELIS, I.; VALE, T. G.; Silva, A.P.; IORIO, Â.; MURY, R.; MESQUITA, S. Profissão docente em contextos populares: notas sobre uma escola privada. In: VIII SEMINÁRIO INTERNACIONAL RED ESTRADO - UCH - CLACSO / II Seminário Internacional de Políticas Educativas en Latinoamérica - UCH, 2010, Lima. Educación y Trabajo Docente en el Nuevo Escenario Latinoamericano, 2010.

LÉLIS, I. Trajetórias de vida de professoras primárias e a constituição do capital pedagógico. 2014. Mimeo.

MURY, R. Profissionalização docente: da aderência à vocação. In: $34^{a}$ REUNIÃO ANUAL DA ANPED, Natal, RN, 2011. Anais... Disponível em: < http://34reuniao.anped.org.br/ images/trabalhos/GT08/GT08-520\%20int.pdf>. Acesso em: 4 out. 2014.

NÓVOA, A. Para o desenvolvimento sócio-histórico da gênese e desenvolvimento da profissão docente. In: NÓVOA, A. Teoria e Educação. n. 4. Rio Grande do Sul: Panoramica Ltda., 1991. p. 109-139.

NÓVOA, A. Os professores e as histórias da sua vida. In: NÓVOA, A. Vidas de professores. 2. ed. Colecção Ciências da Educação. Porto, Portugal: Porto Editora, 2007. p. 11-30.

SETTON, M. G. J. A teoria do habitus em Pierre Bourdieu: uma leitura contemporânea. Revista Brasileira de Educação, Rio de Janeiro, n. 20, p. 60-70, mai./jun./jul./ago. 2002.

TURA, M. L. A observação do cotidiano escolar. In: ZAGO, N.; CARVALHO, M.; VILELA, R. (Org.) Itinerários de pesquisa: perspectivas qualitativas em Sociologia da Educação. Rio de Janeiro: DP\&A, 2003. p. 183-206. 
VALLE, I. R. Carreira do magistério: escolha profissional deliberada? Revista Brasileira de Estudos Pedagógicos, Brasília, v. 87, n. 216, p. 178-187, mai./ago., 2006.

VALLE, I. R. Da “identidade vocacional” à “identidade profissional”: a constituição de um corpo docente unificado. Revista Perspectiva, Florianópolis, v. 20, n. Especial, p. 209-230, jul./dez. 2002.

\section{NOTAS}

${ }^{1}$ A investigação se consolidou como um braço da pesquisa-mãe desenvolvida pelo GEPPE - Grupo de Estudos e Pesquisa sobre Professor e Escola - coordenado por Autor no Departamento de Educação da PUC-Rio: Escolas privadas de setores populares: quem são seus professores?. As abordagens e os instrumentos metodológicos utilizados obedeceram aos procedimentos éticos estabelecidos para a pesquisa científica em Ciências Humanas.

${ }^{2}$ A esse respeito, conferir, por exemplo, Alvez-Mazzotti (2007); Brandão, Manderlet e de Paula (2005); Lélis, Nascimento e Mesquita (2009).

${ }^{3}$ Para o autor (CANÁRIO, 2005), o conceito de mutação deve substituir a ideia de crise da escola. Segundo ele, o conceito de mutação encerra a percepção de que essa instituição tem passado por mudanças e problemas estruturais no seio das sociedades contemporâneas, indicando a necessidade de que a própria forma escolar seja repensada tendo em vista o papel hoje atribuído à escola.

${ }^{4}$ A LDBEN 9394/96 estabelece, em seu Artigo 20, a existência, no Brasil, de instituições públicas, mantidas e administradas pelo Poder Público, e privadas com e sem fins lucrativos. As primeiras - com fins lucrativos - são entendidas como privadas em sentido estrito, mantidas por pessoa(s) física(s) ou jurídica(s). Já as compreendidas como sem fins lucrativos subdividem-se em comunitárias, confessionais e filantrópicas, recebendo, de acordo com a lei, incentivos fiscais.

${ }^{5}$ Dados aferidos tendo como referência a Rais (Relação Anual de Informações Sociais), base estatística do Ministério do Trabalho e Emprego.

${ }^{6}$ Entrevista concedida ao GEPPE em 16/11/2010.

${ }^{7}$ Nome fictício.

${ }^{8}$ Dos 11 respondentes ao questionário, apenas um declarou-se como do sexo masculino. Por isso, utilizamos, neste trabalho, de forma genérica, a denominação "professora" e o gênero feminino, referindo-nos a todo o corpo docente.

${ }^{9}$ Lélis (2014) entende como capital pedagógico aquele "constituído de conhecimentos, atitudes, valores, práticas adquiridos na imersão prolongada em determinadas instituições e não em outras". Indo além dos saberes docentes, curriculares e de experiência, e construído a partir de estilos de vida e das diferentes posições do sujeito social nos diversos campos pelos quais transita. Em especial, no campo da educação, o capital pedagógico "inclui ideias, valores, saberes e práticas que os professores possuem e que vão além do que se convencionou denominar incompetência ou competência técnica".

${ }^{10} \mathrm{O}$ conceito de aderência foi apresentado na dissertação de mestrado intitulada "Profissionalização docente na Escola da Ladeira - entre histórias e trajetórias, o caminho possível”, defendida em 2011 no Departamento de Educação da PUC-Rio por Autor, sob a orientação do Autor.

${ }^{11}$ Para Bourdieu (2007), o estado institucionalizado do capital cultural se configura através da aquisição de diplomas que certificam a posse de determinados conhecimentos por parte de seu portador. Sendo o produto da conversão de capital econômico em capital cultural, ele pode adquirir diferentes valores em situações e momentos históricos distintos. "Pelo fato de que os 
benefícios materiais e simbólicos, que o certificado escolar garante, dependem também de sua raridade, pode ocorrer que os investimentos (em tempo e esforços) sejam menos rentáveis do que se previa no momento em que eles foram realizados" (BOURDIEU, 2007, p. 79).

Recebido: 21/10/2014

Aprovado: 04/05/2015

Contato:

Rita de Cassia Ximenes Mury Rua São Clemente, 283/401, Botafogo

Rio de Janeiro $|\mathrm{RJ}|$ Brasil

CEP 22.260-001 